\title{
"Últimos dias de Carlos Gomes": do mito "gomesiano" ao "nascimento" de um acervo
}

Emerson Dionisio G. de Oliveira*

\section{Resumo}

O presente artigo busca identificar as estratégias utilizadas por dois pintores italianos, no final do século 19, para a representação da morte do compositor Carlos Gomes, na cidade de Belém, em 1896, e o uso que o Museu de Arte de Belém faz dessa "representação" dentro das narrativas de seu acervo. Para tanto, cabem reflexões sobre os processos narrativos da "pintura histórica" e seu uso documental dentro de uma tradição de ler "uma" história a partir da constituição do mito "gomesiano".

Palavras-chave: Acervos. Museu de arte. Carlos Gomes.

\section{"The last days of Carlos Gomes": the "gomesian" myth and the "beginning" of a collection}

\begin{abstract}
The aim of the present article is to identify the strategies of two Italian painters from the last years of the Nineteenth Centrury to represent the death of composer Carlos Gomes that took place in Belem city, in 1896. The use of this "representation" by the Art Museum of Belem in the narratives of its collection is also object of study. For that, we reflect about the narrative procedures of the "historical painting" and its documental employ within the context of a tradition of reading "a" story from the establishment of the "gomesian" myth.
\end{abstract}

Keywords: Collections. Arte museum. Carlos Gomes.

"Carlos Gomes não deixará esperanças dessas. 'Talvez ao chegarem estas linhas ao Rio de Janeiro, já não exista o inspirado compositor, que entrou em agonia', diz uma carta do Pará 
publicada ontem no jornal do Comércio. Pois existe, está ainda na mesma agonia em que entrou, quando elas de lá saíram. Hão de lembrar-se que há muitos dias um telegrama do Pará disse a mesma cousa, foi antes dos protocolos italianos. Os protocolos vieram, agitaram, passaram, e o cabo não nos contou mais nada. O padecimento, assim longo, deve ser forte; a carta confirma esta dedução. Carlos Gomes continua a morrer. Até quando irá morrendo? A ciência dirá o que souber; mas ela também sabe que não pode crer em si mesma." (ASSIS, 1994, p.142).

É desse modo que, no dia 6 de setembro de 1896, Machado de Assis, num artigo da revista "A Semana", escreve sobre a doença que vitimava Carlos Gomes e que o levou à morte catorze dias depois. As linhas de Assis nos mostram como o país acompanhava a doença que acometeu o mais importante músico brasileiro da segunda metade do século 19. Um padecimento público em torno de um "homemmito", que funcionou de diferentes modos.

Nosso trabalho procura investigar um importante artefato da engenharia que constituiu a construção do mito "gomesiano" (COELHO, 1995), a tela "Últimos dias de Carlos Gomes" (1), dos italianos Domenico De Angelis (1852-1904) e seu assistente Giovanni Capranesi (1852-1921), finalizada e exposta em 1899. Da mesma forma, pretendemos visualizar a relação da obra como "representação" dos anos áureos da borracha através do seu lugar na constituição do acervo do Museu de Arte de Belém (MABE).

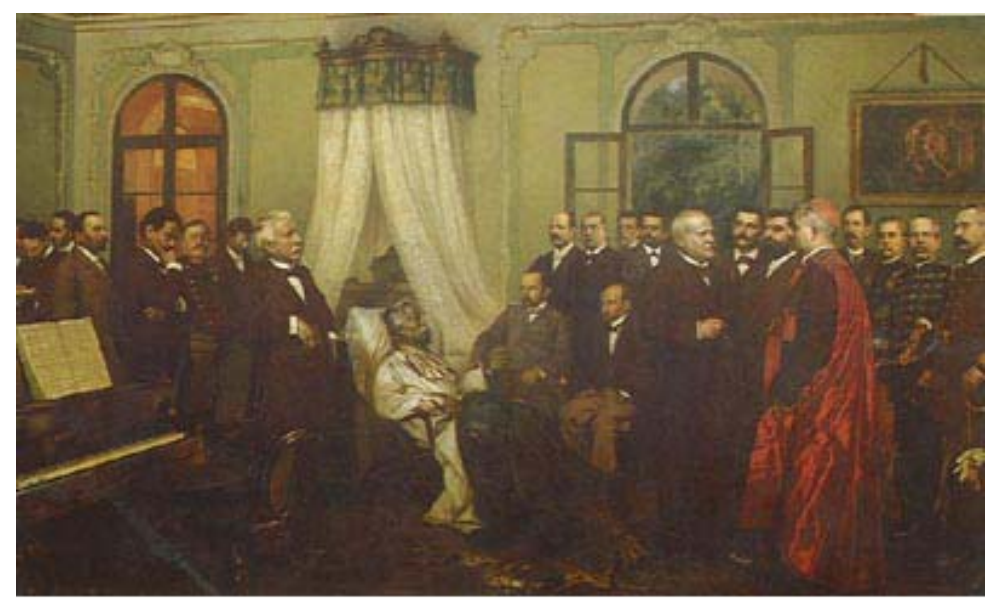

Figura 01 - Úlitimos dias de Carlos Gomes, 1899, de Domenico De Angelis e Giovanni Capranesi. Reproduçāo fotográfica, fonte: BELÉM, Prefeitura Municipal. Fundaçāo Cultural do Municipio de Belém/ Museu de Arte de Belém (MABE). Catálogo de Conservaçăo do Museu de Arte de Belém: memória e inventário. série Caminhos da Cultura. Belém: MABE, 1996. 
Muitos são os critérios à disposição de uma pesquisa que visa à leitura de uma obra polissêmica como o quadro de De Angelis e Capranesi. Nossa abordagem pretende formular hipóteses de como transformar um objeto de arte em fonte histórica. Assim, o conhecimento da obra arremata a produção iniciada pelo artista. Ao mesmo tempo, a obra de arte não existe sem um enquadramento num sistema de referência interpretativa, o que significa que falar de uma obra não é falar apenas dela, mas dos sentidos que se agregam a ela ao longo de sua existência como evento cultural e sujeito histórico. Parte considerável da história de uma obra de arte é conferida pela tradição de sua leitura. Nesse sentido, toda a obra, feita imagem e documento, apresenta-se como esboço, palimpsesto e, de certo modo, sempre inacabada.

Apoiado por autores díspares, como Douglas Crimp (2006), Roger Chartier (1999) e Jorge Coli (2005), compreendemos que o valor de uma obra de arte será diretamente proporcional à força do sentido liberado por ela, a qual decorrerá das imprevisíveis operações que constituem os atos de assimilação e interpretação. A intenção do autor - ou autores - não se comunica senão como índice abstraído das configurações da obra, que pode produzir maior ou menor número de leituras no ambiente cultural em que se insere. Conhecer a história crítica de uma obra e sua condição de produção é dominar o repertório das relações impostas aos espectadores da obra, as quais, obedecendo à configuração sociocultural, oscilam conforme as convicções de cada momento.

Sendo assim, no caso de "Últimos dias de Carlos Gomes", dispomo-nos a não ignorar o fato de que se trata não apenas de uma obra capital para a história da formação simbólica do mito "gomesiano", trata-se também de uma obra-ícone para a história da cidade de Belém e um dos pontos essenciais para a configuração de um museu de arte - o Museu de Arte de Belém (MABE). Todas essas dimensões devem ser entrecruzadas com a própria tradição pictórica ocidental de expor, no leito de morte, personalidades públicas, dando-nos pistas do modo como a morte será representada num objeto artístico, em diferentes contextos culturais e históricos.

Seguimos aqui, dessa forma, o conselho de Chartier, que, tendo em vista uma série de elementos, confere ao historiador a responsabilidade por habilitar suas fontes, sobretudo quando se trata de fontes imagéticas: 


\begin{abstract}
"Uma questão importante para o trabalho histórico é medir a possível distância entre, de um lado, aquilo que é lícito representar e, de outro, os gestos efetivos, as práticas reais. Freqüentemente, os historiadores devem se contentar com o registro das mudanças nos sistemas de representação. Seria temerário concluir demasiado rápido sobre a realidade dos comportamentos a partir de representações codificadas que dependem tanto das convenções ou dos interesses envolvidos no ato de mostrar - pela pintura, pela gravura, pela fotografia - quanto da existência ou da ausência dos gestos que são mostrados." (CHARTIER, 1999, p.81).
\end{abstract}

Ou seja, ao entramos no universo de "Últimos dias...", estaremos dispostos a investigar como essa obra oscila entre representação do real e alegoria ficcional, dentro de seu funcionamento social e de certas "convenções" que demarcaram a chamada pintura acadêmica do final do século 19, cujo modelo guarda particularidades dispares dos atuais modos de conceber e perceber a arte contemporânea, por exemplo. Ao mesmo tempo, pretendemos acompanhar a trajetória narrativa da obra na direção de esboçar uma certa representação da morte de Carlos Gomes.

\title{
1 Viva o Imperador! Viva Carlos Gomes! Viva o Brasil!
}

Antes de investigarmos o quadro do MABE, discutiremos algumas lições oferecidas por pesquisadores que se debruçaram sobre a morte do compositor Antônio Carlos Gomes (2). Optamos por historiadores e musicólogos que problematizaram este tópico em virtude de sua própria ambigüidade: a morte pública e 'privada' do maestro.

O momento da trajetória de Carlos Gomes que nos interessa começa quando o músico desembarca em Belém do Pará, no dia 14 de maio de 1896. Gomes chegou à cidade para presidir o futuro Conservatório de Música do Estado, a convite do então governador do Estado, Lauro Sodré. O compositor vinha da Itália, onde passou uma longa temporada e colheu grandes sucessos com a apresentação de óperas como "O Guarani" (1868, estréia em 1870, no Teatro Alla Scala de Milão), "Fosca" (1872, estréia em 1873, no Teatro Alla Scala de Milão) e "Salvador Rosa" (1874, estréia no Teatro Carlo Fenice de Gênova) (3). 
O músico chegou a Belém já doente e com o diagnóstico de câncer, proferido em Portugal no ano anterior. Ele saiu da Europa com muitas dívidas, e o convite de Sodré lhe cabia mais como uma homenagem do que propriamente como uma oportunidade de continuar sua carreira.

O retorno do compositor ao Brasil fora lido, a partir de sua enfermidade e morte, como regresso do filho genial à pátria. Segundo Coelho, a presença de Carlos Gomes foi, à sua medida, mais uma "conquista" da emergente elite da borracha, à época das folies du látex (COELHO, 1995, p.30-32). Uma elite devotada a consumir um estilo de vida urbano importado dos grandes centros europeus e da capital da República.

O "gênio" que chega aos trópicos encarnava uma representação típica do artista romântico, e mais toda uma ideação da criação romântica voltada ao indivíduo. Tal gênio desdobra-se, no caso de Carlos Gomes, num herói que, nas arestas de suas "identidades", nutria os discursos em torno de uma idéia de nação, de povo e de espírito brasileiro. Foram esses os matizes narrativos que o próprio compositor alimentou com suas obras ambíguas, como "O Guarani" e "O Escravo" (4), na confecção de um ideal de totalidade onde estão conjugados os elementos da cultura popular e os valores da elite oitocentista (5), louvados por uma elite ávida por homens que sintetizassem sua terra, ao mesmo tempo em que propagassem fora daqui o ideal de um país civilizado (COELHO, 1995, p. 94).

Era esta a síntese do mito "gomesiano", que tomou corpo no momento em que o compositor retorna pela primeira vez ao do Brasil, já consagrado na Itália, para a estréia brasileira de sua mais conhecida ópera, “O Guarani”, em 1870:

"[...] foi o ponto máximo da musicalidade nacional. Enfim o Brasil tem um verdadeiro mestre, destacado entre os mestres, sereno e revoltoso, preso às suas origens, que fez ultrapassar nas pautas o território de sua pátria. O povo brada feliz. Viva o Imperador! Viva Carlos Gomes! Viva o Brasil!" (Visconde de Taunay apud FERNANDES, 1978, p.97).

É a partir dessa euforia que o mito "gomesiano" toma nova perspectiva. O heróigênio Carlos Gomes não fora uma criação daquele momento, mas o acúmulo 
anterior de sucessivas representações que emanavam do e sobre a figura do músico. No que concerne às repercussões dessas representações em Belém, dois momentos são importantes: as passagens de Gomes pela cidade, nos anos de 1882 e no ano seguinte. Episódios úteis não apenas ao esforço e ao prestígio da construção e do funcionamento do Theatro da Paz, inaugurado em 1878, como também ao movimento de sedimentação cultural daquela elite (6).

A primeira tentativa de trazer Carlos Gomes a Belém, deu-se em 1880, quando a Companhia Lírica Italiana, que apresentou "O Guarani” no Theatro da Paz, na sua ausência, colocou, "no palco, o seu retrato, envolto pela bandeira imperial, durante todo o espetáculo" (COELHO, 1995, p.98). Em 1882, o músico vem acompanhado da mesma Companhia para nova apresentação de "O Guarani" e, sob sua regência, uma apresentação da ópera "Salvador Rosa". No ano seguinte, Carlos Gomes, acompanhado de uma companhia lírica milanesa formada por ele, volta à cidade para uma temporada, ocasião em que apresentou "Fosca" (7). A partir dessas duas experiências e com a benevolência da imprensa e dos artistas da cidade, quando retorna, em 1896, Carlos Gomes encontra um ambiente em que seu prestígio não fora abalado, distante das dívidas e das oscilações de popularidade européias.

O "mito" chega a Belém e não encontra uma exótica cidade do norte do país, mas, sim, uma cidade que se representava como "próspera", que assistiu, nos trinta anos anteriores à sua chegada, um desenvolvimento econômico sem paralelo em sua história. Belém - como Manaus - viveu naquele período um entusiasmo e uma fé no progresso que foram legitimados e alimentados pela presença de uma vida cultural que se espelhasse nas grandes cidades européias. $O$ entusiasmo fora tamanho que Márcio Souza (8) chega mesmo a defender que, por alguns anos, as duas capitais amazônicas estavam dispostas a rivalizar não apenas com Recife, Salvador e São Paulo, mas também com as capitais, Rio de Janeiro e Buenos Aires (SOUZA, 1994, p.74). Pretensões regadas aos altos preços da borracha no mercado internacional e que não passaram despercebidas aos olhos europeus que chegavam à região, como nos conta Souza: 
"Jean de Bonefous, viajante francês, dá sua impressão do lado sorridente da sociedade da borracha. Belém pareceu-Ihe Bordéus, com 'um movimento de veículos de toda a sorte, um vai-e-vem contíguo, que parece mais um centro europeu do que uma cidade tropical'."

Souza continua:

"Sobre Manaus, outro francês, Auguste Plane, emocionava-se com o Teatro Amazonas: 'A construção é majestosa, quanto ao exterior; a sala é elegante e ricamente decorada. $O$ teto, a obra magistral do pintor De Angelis, é admirável. Bem arejado, bem iluminado, representa uma das curiosidades de Manaus. A mais refinada das civilizações chegou ao Rio Negro'." (SOUZA, 1994, p.112) (9).

Essas percepções do fenômeno que enriqueceu a região continuam de qualquer forma sendo pinceladas dos diários e escritos estrangeiros para, de certo modo, reiterar o mito criado em torno do fenômeno da borracha (10).

\section{Um ateliê e muitos artistas}

A Belém encontrada por Gomes, em 1896, pululava de artistas vindos da Europa e que aportaram na cidade. Entre as dezenas de músicos, pintores, escultores, fotógrafos e atores que chegaram a Belém na última década, estavam os italianos Domenico De Angelis (11) e Giovanni Capranesi (12). Os dois artistas se conheceram na célebre Academia de San Luca, em Roma, e começaram a trabalhar juntos em 1882, dedicados a projetos de criação de caráter sacro, o que lhes rendeu o primeiro convite para vir ao Brasil em 1883. Na ocasião, Dom Antonio de Macedo Costa, Bispo do Pará, os convidou, por intermédio do Vaticano, e com apoio direto do imperador brasileiro, para remodelar a Catedral de Belém, onde ambos executaram, inicialmente, as pinturas da abóbada e mais três telas, hoje presentes nos altares laterais (13).

O ateliê de De Angelis e Capranesi acabou solicitado para outras obras, tanto na cidade de Belém quanto em Manaus. As cidades estavam em pleno frenesi da borracha e num processo de estruturação tanto de sua infra-estrutura quanto de seus aparelhos culturais e religiosos (14). 
Por volta de 1886, a atuação do ateliê dos artistas nas duas cidades amazônicas era tão intensa que De Angelis chegou a fixar breve residência em Manaus, para onde ele foi chamado a trabalhar, na Igreja de São Sebastião. Na mesma cidade, na década seguinte, destacou-se por produzir a pintura do teto no Salão Nobre do Teatro Amazonas, denominada "A Glorificação das Bellas Artes na Amazônia" (1899), com forte "sotaque" barroco. Nesses anos, em diferentes encomendas, eles produziram obras de uma grande maleabilidade, com vocabulários diversos, dentro dos universos do neoclassicismo, do barroco e da pintura romântica, o que nos dá certa idéia dos métodos e dos modos de produção tanto de De Angelis quanto de Capranesi.

Em 1887, em outro exemplo da versatilidade artística, o ateliê (15) foi contratado pelo governo provincial para decorar a sala de espetáculos do Theatro da Paz de Belém. Apoiado por uma equipe de artistas europeus, projetou a pintura do teto, na qual se vê o deus grego Apolo conduzido por um carro puxado por cavalos, ladeado por musas, entrando majestosamente na Amazônia. Também se vê sua irmã, a deusa Diana, na pele de uma tupia. A equipe ainda trabalhou em pintura florais dos camarotes e, mais tarde, na pintura do teto do salão nobre. Na primeira obra (16), vemos a influência da leveza e da dinâmica, ao gosto do mestre italiano Giambastista Tiepolo (1696-1770), que contrasta, por exemplo, com a severidade da composição de "Últimos dias...".

Tanto De Angelis quanto Capranesi receberam uma formação ampla na Itália, onde aprenderam a trabalhar com técnicas diversas, como a pintura parietal, de cavalete e as técnicas do afresco. Foram alunos de Cavalieri Carta Alessandro Marini. Essa mobilidade entre técnicas e estilos é indicativa de que estamos próximos de artistas que estão mais ligados à tradição da artesania italiana e do restauro defendida por Camillo Boito (CHOAY, 2001, p.164-173) do que das vanguardas européias que pululavam no último quarto do século 19.

O descolamento entre o norte do país e o ateliê localizado na Praça Vittorio Emanuele, em Roma, foi intenso nesse período de quase vinte anos. Na mesma época em que estavam dedicados à produção da obra do MABE, De Angelis e, especula-se (COELHO, 1995), principalmente, Capranesi debruçam-se, também, 
sobre um conjunto de telas no ateliê romano para o Teatro Amazonas. O conjunto (17) compreende temas da paisagem amazônica, e uma delas, em especial, baseia-se em "O Guarany", que é, ainda hoje, a maior das pinturas na parede da sala que conduz ao interior do teatro, onde encontramos "Peri salva Ceci do incêndio", conforme o argumento da ópera de Carlos Gomes (inspirada na obra homônima de José de Alencar)(18). Essas telas não foram assinadas, o que confirma nosso juízo sobre o caráter artesanal do ateliê dos artistas romanos. Não assinar uma obra já no final do século 19, seja no corpo da obra ou no verso da tela, é algo atípico para artistas do circuito acadêmico, ligados à tradição das competições nos salões e para aqueles já inseridos no mercado de arte (WHITE. H; WHITE, C., 1993, p.43-45).

O status desses artistas não pode ser subestimado, pois, da formação ao trânsito pelas Belas Artes na Europa, é de reconhecido interesse para compreender-se a "importação" de conceitos artísticos europeus para regiões periféricas. De Angelis, por exemplo, será exaltado, nesse período, como um dos principais arquitetos do gosto da região Amazônica, ao lado do pintor russo Davi Widhopff (1967-1933), que, uma década depois do pintor italiano, será contratado para ocupar as cadeiras de pintura do recém-criado Liceu Paraense e da Escola Normal (FIGUEIREDO, 2003, p.42). Cena compartilhada, também, com outros estrangeiros: o casal Maurice e Louise Blaise, Antonio Leonardo, François-Auguste Biard, Felipe Fidanza e José Leon Righni. Esses "artesãos" ocuparam o centro da produção artística da região, até que artistas brasileiros, no início do século 20, reivindicarem tal posição (19).

\section{A morte pela arte}

O que nossa análise alcança não é a veracidade dos fatos que circundaram a morte de Carlos Gomes, mas o papel de uma obra de arte na construção da representação dessa morte "bela". Houve, desde a chegada de Carlos Gomes ao país, a necessidade de construir-se uma narrativa "edificante" que, embora contrariasse as prerrogativas de outras narrativas, tentou impor-se com atributos da veracidade histórica e o fenômeno paradoxal que ela engendra. O que se tem de autêntico nessa narrativa é menos as qualidades artísticas do compositor brasileiro e mais a vontade de constituir um mito que ofertasse corpo aos desejos de uma república recém-criada, carente de mitos próprios (CARVALHO, 1995). Tal narrativa irá 
reconstruir a história de Carlos Gomes a partir de sua morte, dando ênfase a aspectos de sua obra e vida que corroborassem as perspectivas.

No universo do século 19, principalmente a partir de um olhar romântico, a morte torna-se uma obsessão, uma vez que alimenta em si a inadequação do homem ao mundo, ao mesmo tempo em que nutre a nostalgia de possível devir espiritualizado. Até em seus prazeres mais excessivos, o homem do oitocentos é atormentado pelo sentimento da morte e pelo fascínio do fim.

Foi nesse século que se definiu uma mudança efetiva nas relações sociais perante à morte. Os motivos foram apontados por estudiosos diversos como Philippe Áries (1988), Michel Vovelle, Jean Delumeau, na Europa, e Cláudia Rodrigues (2005), João José Reis (1991), Maria Lucia Marcílio (1983) e Geraldo Coelho (1995), no Brasil, apenas para citar alguns nomes. Ariès mostra-nos que a morte nos oitocentos passa a ser acompanhada no leito privado. Sob rituais e manifestações de preces e lamentos, gestos dramáticos, daquilo que Marcílio denominou como "afetividade macabra" (MARCÍLIO, 1983, p.63). O estudioso francês salienta o culto dos túmulos individuais ou familiares, da sepultura particular e as peregrinações aos cemitérios (20). De certo modo a morte passa por uma secularização ou, num sentido diverso, por uma "descristianização" segundo Vovelle (21).

A passagem do aspecto público ao privado da morte, banindo-a das preocupações sociais do homem ocidental, segundo Áries (22), conferiu a cerimônias públicas um caráter excepcional, uma vez que tal recurso deveria ser reservado às figuras públicas. Nesse aspecto, Coelho levanta a importância dos velórios públicos na França revolucionária e, sobretudo, as cerimônias fúnebres que marcaram o retorno dos restos mortais de Napoleão Bonaparte à Paris, em 1840, e as celebrações dedicadas a Victor Hugo, cujo cortejo fora exaltado pela mídia como "apoteótico" (COELHO, 1995, p.50). No Brasil, três mortes antecederam o gosto positivista pelo culto aos mortos (23). As cerimônias fúnebres de Benjamin Constant, em 1891; o sucesso popular das pompas dedicadas a Floriano Peixoto, morto em 1895; e o antecessor de ambos, o intelectual Aureliano Cândido Tavares Bastos (24), morto em 1876. Todos receberam cerimônias projetadas para a construção de um novo modo de morte, uma morte prestigiada e bela. 
A morte bela - obtida ou consentida por meio de grandes valores como a honra, o amor e a beleza - era ritualizada na ambivalência do mundo privado e na esfera do mundo público, o primeiro como canal para a exaltação da afetividade, e o segundo pela via do luto ostensivo, da expressão da dor social. Nesses dois aspectos não podemos deixar de indicar o lugar que "Últimos dias..." ocupa na série de obras que retratam homens e mulheres em seus leitos de morte, desde o final da Idade Média. As mudanças são visíveis na arte da morte em um lugar especifico: o leito do convalescente.

Muitos são os exemplos dentro da tradição ocidental da arte: "A morte de São Martino", afresco de Simone Martini, de 1321, presente na Basílica Inferior de São Francisco, em Assis, Itália; "A morte de Santa Clara", obra de 1410, do artista conhecido como Mestre de Heiligenkreuz; "A morte da Virgem", tela sobre óleo de 1605-1606, de Caravaggio; “A morte de Germanicus", de 1627-1628, de Nicolas Poussin; "A morte de Sócrates", de 1787, executada pelo artista francês JacquesLouis David; Napoleão em seu leito de morte, gravura anônima dos anos 20 do século 19 e seu par "A morte de Napoleão na Ilha Santa de Helena" de 1823, de autoria de Karl-August von Steuben. Obras de diferentes tônicas sociais, vocabulários estéticos e leituras do "morrer" que ao lado de muitas outras formam um elenco precioso que muito provavelmente afetou, senão a formação dos artistas italianos, o próprio conceito da representação da morte na segunda metade do oitocentos.

Tomemos apenas as duas últimas obras. O que nos chama atenção é o papel central conferido à cama que atravessa as obras, no sentido horizontal, na obra anônima, e no sentido inclinado, na obra de Steuben. Em ambos os casos, o personagem central é Bonaparte, embora alguns elementos desviem o senso dramático de seu corpo, como é o caso das duas crianças. De qualquer modo, o sentido narrativo reside no padecimento e na morte do personagem central, enquanto os demais retratados figuram como elementos subordinados, que dão dinâmica aos elementos expressivos alternados entre pesar, lamento, prostração, resignação e toda uma gama de elos sentimentais que podem ser atribuídos às suas representações. 
No caso de "Últimos dias de Carlos Gomes" (25), a configuração espacial é diferente, o que afetará a constituição expressiva da obra. Se nossos olhos seguirem da esquerda para a direita, teremos a construção de seis grupos organicamente ligados entre si. A "cama" do maestro surge como um elemento delimitador, e o piano à sua direita corta a obra numa leve diagonal. No primeiro grupo, encontramos dois homens (os pintores italianos) entretidos com um terceiro que toma notas, o jornalista Licínio Silva, presença importante na cena da morte do músico.

$\mathrm{Na}$ direção do maestro, já no segundo grupo, temos dois homens que olham fixamente para o maestro, o enfermeiro Raul Franco mais recuado e à sua frente, o professor Ernesto Dias, com a mão no queixo - uma demonstração única na obra. Completando o segundo grupo, temos o coronel Gama Gosta que nos olha e o músico Clemente Ferreira, ao fundo, de cabeça baixa e, no primeiro plano, Visconde de São Domingos, recostado sobre a cadeira do piano. O terceiro grupo é formado pelo próprio maestro recostado sobre uma chaise-longue, conversando com o governador do Pará, Lauro Sodré, que se encontra sentado ao lado do vicegovernador, Gentil Bittencourt, atento às "palavras" do maestro. Gomes gesticula para os seus interlocutores num movimento lento, comedido.

No grupo seguinte, atrás dos dois políticos sentados, vemos um conjunto de quatro homens que fitam ou o músico ou o espectador: o senador e intendente Antonio José de Lemos; os jornalistas João Marques de Carvalho, Antonio Leite Chermont e João de Rego. No quinto grupo, encontramos os médicos José Paes de Carvalho, Miguel Pernambuco e Numa Pinto conversando com o bispo Dom Antonio Manoel de Castilho Brandão. No último grupo, outros quatro homens, desta vez, mais recuado e sozinho, o deputado federal Pedro Leite Chermont e, a sua frente, o Capitão Serra Pinto (inspetor do Arsenal da Marinha), o General Cláudio do Amaral Savaget (chefe do $1^{\circ}$ distrito Militar) e o Coronel Augusto de Vasconcelos Chermont (inspetor do extinto Arsenal de Guerra).

A obra reforça o quadro geral em que Gomes fora "recebido" em Belém. Ali está o músico enfraquecido, padecendo com digna aparência sobre os olhos de uma afetividade coletiva, simbolizada por aqueles vinte $e$ dois homens que o 
acompanham. Figuras importantes da Belém do final do século 19 (26). Jornalistas, músicos, políticos, militares, a Igreja. Também compõem a cena o piano do maestro, com partituras de "O Guarani", e, à direita superior, um quadro representando o rapto de Ceci por Peri, cena da mesma ópera. Neste caso, tem-se a necessidade de marcar a profissão do retratado e de dar continuidade a uma série de relatos e fotografias que "dizem" que Carlos Gomes morreu com suas partituras aos pés (27).

O "tempo" na obra do MABE é o outro personagem presente. Ele inscreve-se graças às duas janelas ao fundo. A situada mais à direita encontra-se aberta, e podemos ver uma paisagem verde ao fundo, sob a luz do sol, enquanto a janela da esquerda encontra-se fechada e, além do vidro, vemos a continuação da arquitetura do edifício sob uma iluminação noturna. A escolha dessas duas dimensões de luz serve como pista temporal, inscrevendo sobre a obra a possibilidade de se ler que aqueles homens acompanharam as últimas horas do maestro, "dia e noite".

O quadro possui, ainda, qualidades luminosas, feitas de vibrações, ora discretas, entre os tons escuros, ora com transições e oposições acentuadas de vermelho $x$ preto e de verde $x$ branco-amarelo. Há uma arquitetura formal promovida através de etapas claramente isoladas, que se articulam, de modo lento, de um grupo ao outro, onde o movimento só tem lugar como um sistema de tensões e não enquanto ilusão dinâmica. Nesta obra, cujo mote central são os retratos, estamos muito distantes daquele "Tiepolo" do Theatro da Paz, pois o rastro da pincelada desaparece, o desenho articula a cor, subordinada à dinâmica espacial.

O sofrimento do maestro não foi escolhido de modo casual, pois seus longos meses de agonia sintetizam, muito mais que sua morte, as operações simbólicas desenvolvidas para a constituição do mito "gomesiano". Os artistas italianos foram, certamente, influenciados por essa atmosfera, que criará em torno desse sofrimento e morte toda uma série de imagens poéticas (28) e apaziguadoras. De Angelis e Capranesi deixaram sobre a tela uma visão que estava em consonância com o que, segundo Coelho e Marques (29), esculpiu uma cena bela para sua morte.

Em contrapartida, se deixarmos as convenções sobre a obra de lado, poderemos verificar o quanto a construção cênica da obra pode nos revelar sobre a "morte bela" 
de Gomes. Façamos um movimento de imaginação para verificar quanto os artistas promoveram a cena da morte com uma alegoria sutil. Eliminemos a figura do maestro, colocando, em seu lugar, o músico sentado normalmente, sem a assistência da manta, e rebatizemos a obra de "Sarau" ou "Reunião". Nenhum elemento a mais seria modificado, e a cena seria outra, talvez a de um concerto privado, prestes a acontecer ou já terminado.

É certo, que tal movimento de imaginação possui a sua fragilidade. Primeiro porque, se o piano ali está como símbolo e equipamento de trabalho do gênio, também ali estaria para indicar uma récita doméstica, que já teria sua hipótese contestada, veementemente, pela ausência do público feminino, algo impensável na tradição acadêmica do século 19. O que já seria apropriado para uma reunião política, por exemplo. De qualquer forma, nosso exercício atinge o contento de nos indicar quanto o quadro mostra, de forma quase casual, o sofrimento de Carlos Gomes. Como se, naqueles momentos, o ato de morrer fosse mais uma das deliberações de um conselho de cavalheiros que se reúne numa noite para conversações.

É nesse ponto que as demais obras aqui citadas se afastam de "Últimos dias...".Nos trabalhos onde vemos a morte de Napoleão e Lorde Nelson (KOSSOY, 2000, p.14), o sofrimento de seus pares é visível, senão acentuado, como forma de constituir o drama. O silêncio, no caso da obra do MABE, diz muito sobre o modo "celebrativo" da própria obra e, provavelmente, muito pouco sobre o momento da morte do maestro. A preocupação com os elementos retratistas e a elevação da atenção para os demais grupos no quadro mostram o quanto a obra é, também, um ato de propaganda das ações que levaram aquele grupo, aquela elite, a receber o músico em Belém, perpetuando-se à sua sombra.

Comparada à fotografia de Felipe Fidanza (30), a obra dos italianos é apenas uma reedição da construção de imagens-símbolos. A foto, que percorreu a imprensa com a legenda "Carlos Gomes no seu leito de morte", mostra seu corpo sobre uma cama, num ambiente austero, cujos detalhes centrais residem sobre o chão, ao lado do leito, onde podemos ver partituras e uma almofada com uma lira de cinco cordas. $\mathrm{O}$ modo como esta última se acha localizada denuncia que toda a cena fora montada 
para a produção da fotografia, algo comum para os métodos dos estúdios fotográficos daquela época (KOSSOY, 2000).

Isso nos leva ao território do discurso da pintura de contornos acadêmicos e românticos. "Últimos dias..." possui as ambições da pintura de gênero histórico, considerada hierarquicamente superior aos outros - retrato, natureza morta, paisagem -, porque os contém, numa articulação complexa, imposta pelo princípio de narração que organiza toda a obra.

Artistas acadêmicos, mesmo dentro de uma formação versátil como a de De Angelis e Capranesi, preocupam-se com o valor histórico do projeto e suas ressonâncias naquilo que podemos denominar como real. Suas ambições estão voltadas à síntese de cenas que comportem não apenas a realidade como julgavam ter acontecido, mas como uma idéia de história que deve ser "retocada" por meio de elementos simbólicos que signifiquem para além da própria obra. Sendo assim, não nos parece casual que os dois artistas estejam retratados ao lado do jornalista, numa indicação implícita da proximidade dos deveres de suas profissões.

Mesmo com a ajuda desses profissionais, a facilidade com que a morte, e, por conseguinte a imagem de Carlos Gomes foram utilizadas e assimiladas pelo imaginário republicano, mesmo sendo o músico, sobretudo, um símbolo da política cultural do Império, pode servir a outros historiadores como pista para investigar as mudanças das formulações simbólicas entre um regime e outro. Talvez ambos tenham utilizado o mesmo mecanismo de constituição de uma "nacionalidade atemporal", que, segundo Maria Alice Rezende de Carvalho, consiste na:

"[...] descontextualização do agente civilizador, o artista, o intelectual, o cidadão do Império brasileiro, todos diretamente referidos e organizados em relação ao Estado, de seu meio natural. Como estranho ao meio, sem vínculos constitutivos com a realidade selvagem americana, sua identidade se dava com a continuidade da civilidade européia." (apud SALLES, R., 1996, p.101).

Hipóteses que precisam de outras abordagens, mas que podem dizer algo sobre o quadro do MABE e que nos orientam a questionar os modos de constituição das 
obras de arte desse período, seu valor como elemento de comunicação de uma "história real".

A pintura de gênero histórico era marcada por um forte caráter oficializador e ornamental, que simbolizava a grandeza e o esforço da construção política e cultural, principalmente, do II Reinado e dos primeiros anos da República. Oficialismo e ornamentalismo que estavam inseridos no contexto mais geral da produção artística européia, voltada para o mercado dos aparelhos estatais, montados e mantidos durante o período monárquico (SALLES, R., 1996, p.93-113) (31). Esse elo com o universo europeu, uma certa "fantasia da civilização" (32), como vimos, é mantido de várias formas: com a concessão de bolsas de estudos na Europa aos artistas brasileiros (Carlos Gomes); pela transferência temporária de artistas europeus ao país (Jean-Baptiste Debret); ou, ainda, no último quarto do século 19, pela chegada de imigrantes (caso de Eliseu Visconti).

No entanto, mesmo esses postulados devem ser verificados com cuidado, e não podem impor-se numa interpretação da obra, não podem antecedê-la, pois, caso isso ocorra, estaremos realizando uma ratificação de um processo discursivo que se impõe sobre a obra e não investigando seus modelos de funcionamento.

Assim, vamos discutir um pouco mais sobre essas armadilhas que tangem a interpretação de imagens, e mais especificamente de obras de arte.

\section{0 lugar da fonte}

Um ponto da nossa proposta está voltado à investigação das possíveis leituras "predominantes" que o quadro suscitou ou acumulou desde o final de século 19. Algumas especulações poderiam nos levar a traçar um paralelo entre esse "documento" e as representações públicas que Carlos Gomes vem adquirindo década após década, na mesma proporção que uma visão mais panorâmica de "Últimos dias..." poderia nos levar à trajetória da ópera no país. Contudo, embora esses venham a ser temas fascinantes, nossa pesquisa limita-se a compreender um pequeno átomo desse universo de possibilidades que se apresentam. 
Partimos para compreender o papel, o lugar e a leitura que a obra suscitou dentro da própria instituição que a guarda, o MABE, na última década. Esse assunto, que nos é muito caro, pode ser verificado a partir de outros dois documentos: um catálogo intitulado "Tempo passado, tempo presente: acervo do Museu de Arte de Belém", de 1997; e um CD-ROM chamado "Museu de Arte de Belém: museu e acervo", de 2001. Trata-se de dois documentos oficias do museu que procuram apresentar, no formato de catálogo (em mídias diferentes), parte do acervo da instituição.

O catálogo de 1997 dá à obra um papel de destaque, não apenas por reproduzi-la em página dupla (33), mas, sobretudo, na medida em que, no texto que abre o catálogo, assinado por Janice Lima, intitulado "Da origem à espiritualidade do acervo", podemos encontrar, como voz que autoriza a gênese da coleção, a seguinte citação do intendente Antonio Lemos:

\footnotetext{
"No sentido de ir preparando uma galeria de télas de pintores nacionaes e outros de nomeada, a fim de as expor em salão apropriado, quando o governo municipal de Belém dispuzer de edifício próprio para a installação sua e de diversos departamentos, e cujo início está na tela de De Angelis, que recorda os últimos momentos de nosso caro Carlos Gomes, tenho feito acquisição de quadro de Parreiras, T. Braga e C. Azevedo, os quaes já decoram o salão do Conselho Municipal (1908)." (PREFEITURA..., 1997, p.10).
}

A citação insere "Últimos Dias..." em outro universo de significação. A tela passa, do ponto de vista de uma história museal, a símbolo da gestação de uma coleção que só foi instituída em 1983, com o nome de Pinacoteca Municipal de Belém, passando à denominação atual três anos depois. O crédito que o museu confere à obra como signo fundador não deixa de referenciar aquilo que o próprio catálogo define como a “era Lemos”, nome do intendente, que dá, também, nome ao Palácio onde está hoje localizado o MABE.

Essa relação entre a obras de De Angelis e Capranesi e a "figura" de Lemos não é casual. Como já dissemos, "Últimos Dias..." fora apresentada à cidade em 17 de setembro de 1899, no Salão de Honra da Intendência, no palácio Antonio Lemos, onde permaneceu até 2 de agosto de 1988, quando foi transferida para a sede provisória do Museu da Cidade de Belém (Mubel). A obra permaneceu na reserva 
técnica deste museu até junho de 1993, momento em que fora restaurada. "Últimos Dias" retornou ao Palácio Antonio Lemos em outubro deste mesmo ano. Mas apenas em 12 de janeiro de 1994, a obra volta à sala de origem aos olhos do público. O retorno ao Palácio, marcava a própria mudança do MABE para este edifício, que até então sempre esteve ligado às funções da prefeitura Municipal de Belém.

No CD-ROM, a filiação da obra ao nome de Lemos perde o acento. Aqui o território da obra é direcionado aos artistas, uma vez que temos acesso à obra a partir de sua localização espacial dentro da sala "Deangelis" (grafia original), nome dado à sala apenas em 2002. Essa nova significação é possível porque esse catálogo está dividido em duas partes: museu e acervo. A primeira versa sobre a história "administrativa" do museu e de seu palácio-sede e volta-se para a memória de Lemos, enquanto na segunda, as obras são apresentadas a partir de seu conteúdo histórico-crítico e estético. O vínculo entre o intendente e a obra aparece, portanto, de modo indireto.

Um ponto curioso que merece alguma atenção é o fato de que, embora o museu tenha em seu acervo cinco importantes retratos (34) com a técnica a óleo caracterizando personalidades históricas, nenhum deles é indicado como obra capitular do acervo. Esses quadros, que seguem as clássicas definições naturalistas, típicas dos retratos acadêmicos, estão ausentes dos catálogos, o que potencializa a obra de De Angelis e Capranesi como sendo a única desse gênero (retrato histórico). Talvez resida aqui o que Coli denomina de preconceito contra uma tradição acadêmica. Para este historiador da arte, os critérios de seleção e compreensão da arte do século 19 foram contaminados pelo discurso modernista e engessados pelas ditaduras classificatórias da própria história da arte. "Os estudos sobre a pintura dita 'acadêmica' só agora tomaram impulso, e inúmeras zonas ficam ainda na sombra" (COLI, 2005, p.53).

O embaraço produzido por uma história da arte brasileira que, até há pouco, foi incapaz de produzir juízos e pesquisas exteriores ao discurso modernista que vê a produção do século 19 como um esforço meramente burocrático de ilustrar o cotidiano e a história, só não supera o apego do museu por uma obra "gênese" de 
seu acervo que pode servir de via para compreender que momento da história da cidade de Belém o MABE pretende celebrar. A questão da única obra a rivalizar com "Últimas Dias..." pertencer ao mesmo período - "A fundação da cidade de Belém" de Theodoro Braga, de 1908 - dá-nos mais propriedade para indicar a direção do uso da história da arte para conservação de um mito histórico, o mito da cidade próspera, economicamente pujante, culturalmente visível. É nesse ponto que o mito "gomesiano" encontra-se com a prática narrativa do museu. Ambos estão a serviço da manutenção da história folies du látex.

O problema que a manutenção de uma única vertente dominante para a constituição de um acervo acaba por jogar todas as demais peças num plano secundário. Sabemos que museus podem ser reféns de suas próprias construções narrativas (BREFE, 2005) e demandar anos para construir mesmo um processo crítico a respeito dessas construções.

Outro ponto, talvez o mais grave, é que a própria obra passa a sofrer com uma nomenclatura que lhe define e esgota-se em si. Para além de uma leitura formal, reparemos, por exemplo, que o quadro que possui como função primeira dar corpo à "era Lemos", como indica o texto do MABE, também pode funcionar em outras direções. Um exemplo disso é a presença da personagem em primeiro plano, recostada sobre a cadeira do piano, na porção centro-esquerda da obra, o Visconde de São Domingos. Numa atitude atípica na composição, ele está olhando para o grupo onde se encontra o arcebispo de Belém e parece funcionar como contradiscurso à rigidez e à formalidade das demais personagens. Não só seu gesto corporal mais ousado e informal, mas também porque sua cabeça de perfil dobra a do próprio maestro, num ângulo inclinado. Esse breve sinal, dentro de toda a demora e intencionalidade do trabalho que um projeto como esse exige, surge quase como um elemento cômico de cena, na acepção que Bergson dá este conceito (35).

Essa indicação mostra o quão complexo o uso narrativo dado por uma instituição museal a um bem específico. E o quão pode ser o universo da produção de imagem e, também, quão móveis podem ser as delimitações do campo interpretativo. Poderíamos, por exemplo, abrir espaço para entender porque os artistas optaram 
por um elemento exótico apenas num ponto da cena - o tapete de pele de onça -, ou para refletir sobre a posição social de cada personagem, seu agrupamento e distância do maestro. Exemplos que, de fato, demonstram que, no campo da imagem, como em qualquer outro processo de construção e atribuição de sentido a uma fonte, as possibilidades sempre derivam das questões dos próprios pesquisadores, algo próximo à advertência de Coli: "Os historiadores costumam apenas encontrar aquilo que procuram" (COLI, 2005, p.25).

\section{Notas}

(1) Figura 1. Reprodução fotográfica retirada do Catálogo do MABE, cf. PREFEITURA, 1996.

(2) Carlos Gomes nasceu em 1836, na cidade paulista de Campinas. Suas noções musicais fundamentais foram aprendidas com o pai músico, Manoel José Gomes, e já em 1854 compôs sua primeira obra, a "Missa de São Sebastião". Em 1860 mudou-se para o Rio de Janeiro, onde estudou no Conservatório Imperial de Música. Um ano depois compusera "A noite do Castelo" e, em seguida, em 1862, "Joana de Flandres", ambas óperas com forte temática romântica. Em 1863, parte para Itália, onde compôs grandes sucessos, como a ópera "O Guarani”. cf. NOGUEIRA, 1996 e MARQUES, 1971.

(3) A indicação de que essas óperas foram bem-sucedidas na carreira do compositor brasileiro não significou que a composição, a produção, a montagem e a recepção da crítica e do público foram semelhantes em todas as peças, bem como para as demais óperas ("O Condor" e "Maria Tudor"), cf. BETTENCOURT,1945, onde podemos encontrar a reprodução de trechos de cartas do compositor.

(4) A ambigüidade se inscreve no fato de que estas óperas, que foram associadas aos discursos indigenista e abolicionista, apresentam, contudo, procedimentos narrativos europeus. "O Guarani" é o exemplo máximo da tentativa de "gênese da nacionalidade brasileira, quando a história da colonização, a natureza e o índio estão presentes como elementos centrais", como nos indica Salles, comentando o romance de José Alencar. No entanto, quando a obra é transposta para ópera de Carlos Gomes, os elementos musicais e a língua são estrangeiros, enviesando o sentido "ideal" da obra e sua representação de "nacionalidade"; cf. SALLES, R., 1996, p.109.

(5) Coelho discorre sobre esse tema, traçando paralelos entre as idéias de gênio, nação, povo com a de História, cf. COELHO, 1995, p.22.

(6) "A exaltação pública manifestada quando da passagem de Carlos Gomes por Belém expressaria, dessa maneira, o reconhecimento do valor estético e do componente sentimental da sua obra, como os grandes clichês do seu imaginário, fonte de onde emergiu o mito do Carlos Gomes herói romântico da música brasileira e gênio nacional". cf. COELHO, 1995., p.109. 
(7) Vale ressaltar que nessa última passagem, a temporada fora interrompida por dois fatores: problemas financeiros e o temor por parte dos artistas de uma epidemia de febre amarela, cf. MARQUES, 1971, p.188.

(8) Nascido em Manaus, romancista, dramaturgo, roteirista e cientista social pela Universidade de São Paulo. Foi professor convidado da Universidade da Califórnia, Berkeley, escritor residente nas Universidades de Stanford e Austin, Texas. Autor de obras como "Galvez", "Imperador do Acre", "Mad Maria" e "Mundo Perdido". Obras alicerçadas em pesquisas históricas. No momento, dedica-se à tetralogia "Crônicas do Grão-Pará e Rio Negro", tendo já publicado dois volumes: "Lealdade" e "desordem"; cf. site do escritor, disponível em <http://www.marciosouza.com.br/interna.php?nomeArquivo=vida>. Acesso em 19 mar. 2007.

(9) A tempo: Auguste Plane foi um escritor de "L'Amazonie. A travers l'Amérique Équatoriale" (Paris: Librairie Plon, 1903).

(10) "Esses viajantes deixaram relatos bastante ricos sobre Belém. É o caso de Reginald Koettlitz, Affonso d'Escragnolle Taunay, Jean de Bonefous e dos vários trabalhos de Paul Walle e Euclides da Cunha. Todos eles importantes viajantes, dotados de preocupações críticas, no entanto, estiveram envolvidos pelas ilusões discursivas que fundam a base mítica de Belém. Obviamente, em seu tempo, todos esses autores viram uma Belém imersa na riqueza do látex ou 'ainda' imersa na riqueza do látex, o que, antes de afastar a dimensão acrítica da sua análise da cidade, serve para demonstrar que o lugar de fala 'Era da Borracha' surge de uma situação histórica verificável, fundadora, porém já então permeada de contradições discursivas.”, cf. CASTRO, 1995.

(11) De Angelis nasceu em Roma em 1852, estudou na célebre Accademia di San Luca com principais professores os Cavalieri Carta e Podesti, bem como Alessandro Marini, esse um conhecido retratista daqueles dias. Na Itália trabalhou em importantes obras decorativas como Palácio Borgehse e na Igreja Isidoro Alle Terme. cf. PÁSCOA, Márcio. A vida musical em Manaus na época da borracha (1850-1910). Manaus: Governo do Estado do Amazonas, 1997.

(12) Nascido em Roma, em 1952, também estudou na Accademia di San Luca. Iniciou sua carreira ao lado de De Angelis. Foi professor da Escola Livre de Pintura de Roma. Foi um pintor e resturador muito solicitado no início do século XX. Além do Brasil, Capranesi também realizou a obras para Catedral de Buenos Aires em 1909; cf. ZOCCHI, Arnaldo. Opere e corredo artístico di Giovanni Capranesi. Roma: Galeria de Arte Giacomini, reimpressão, 1991, p.24.

(13) O escultor italiano Luca Carimini fora um dos primeiros artistas dessa onda de desembarques de artistas estrangeiros em Belém, na era da borracha. Em 1867, ele fora contratado para realizar o altar-mor da mesma igreja.

(14) A equipe contava ainda com Adalberto Andreis, Francesco Alegiani, o escultor Enrico Quatrini e o arquiteto Sílvio Centofanti; cf. GALETTI, U.; CAMESASCA, E.. Enciclopedia della pintura italiana. Itália: Aldo Garzanti, 1950.

(15) A importância dos ateliês nessas empreitadas é fundamental para compreendermos como decoração, arquitetura e artes plásticas eram serviços comuns ao mesmo ateliê. Em "O Theatro da Paz e sua história", a pesquisadora Rose Silveira chama atenção para outros dois ateliês, o francês Carpezal e o do brasileiro Amaral: 
“Em 1890 foi inaugurado o famoso pano de boca, que celebra a República e a afirmação do positivismo no Pará. O painel 'Alegoria à República' reúne, de forma ufanista, índios, mestiços e lusitanos, saudando os novos tempos. O painel foi pintado no ateliê Carpezat, em Paris, mas ainda há dúvidas sobre a sua autoria: poderia ter sido feito por Carpezat, como se convencionou registrar, ou pelo cenógrafo pernambucano Chrispim do Amaral, que estudou na Itália, trabalhou na França e realizou cenografias no Theatro da Paz e no Teatro Amazonas." cf. <http://www.theatrodapaz.com.br/historico3.htm>. Acesso em: 27 jul. 2006.

(16) Nos anos 30, um desabamento da pintura do teto do Foyer destruiu completamente a obra dos artistas italianos. Idem.

(17) Entre 1897 a 1899 foram feitas no salão nobre do Teatro Amazonas diferentes obras: "Plafond", alegoria pintada por Domenico De Angelis, sob o título "A Glorificação das Belas Artes na Amazônia"; tapeçarias ao estilo gobelins, fixando aspectos da paisagem amazônica, usos, costumes, fauna e flora; e a tela principal intitulada "O Guarani, quando o índio Peri salva Ceci do incêndio"; também há um óleo sobre tela representando a segunda ponte de Manaus no dia de sua inauguração a cinco de julho de 1896. Pinturas de circunstância representando animais típicos do universo amazônico, cf. LOCKHART, 2000.

(18) Sobre a relação entre a obra literária e a ópera, cf. MAMMI, 2001; sobre a obra de Alencar, cf. Alfredo Bosi, “Um mito sacrificial: o indianismo de Alencar”, In: Dialética da colonização. São Paulo: Cia. das Letras, 1992.

(19) Esse foi o caso de Theodoro Braga que, em poucos anos, toma a cena da produção das artes plásticas na cidade Belém, tanto como artista, mas, principalmente, com a publicação de "A arte no Pará, 1888-1918: retrospecto histórico dos últimos trinta anos", cuja particularidade essencial, como nos mostra Figueiredo, será produzir uma gênese da arte da região somente a partir do ciclo da borracha, eclipsando ou ignorando, por completo, toda produção artística anterior. Cf. FIGUEIREDO, 2004, p.39.

(20) Os cemitérios são o local privilegiado para compreender o assunto. O fechamento do cemitério dos Inocentes, em Paris, em 1780, já adiantava uma série de controvérsias que circularam em torno desse localritual. A urbanização do século 19 aguçou o debate magistralmente estudado por João José Reis em seu "A morte é uma festa", sobre revolta da população de Salvador contra a "privatização" (termo nosso) dos serviços fúnebres, em 1836. Também se dedica a esse assunto Cláudia Rodrigues, numa abordagem diversa sobre os sepultamentos na cidade do Rio Janeiro nos séculos 18 e 19; cf. REIS, 1991, p.77; RODRIGUES, 2005 , p.158.

(21) cf. RODRIGUES, 2005, p.338. O trabalho de Rodrigues é importante nesse aspecto, na medida em que investiga as formas de morrer e sepultar na cidade do Rio de Janeiro nos séculos 18 e 19 . O debate que ela realiza sobre as consonâncias e discordâncias entre Áries, Vovelle e Delumeau muito nos ajudou a pensar que há, antes, vários tipos de morte e as causas dos novos hábitos obedece a geografias sociais e culturais diferentes. A morte de um homem célebre, nosso assunto aqui, é apenas uma das possibilidades narrativas dessa questão; cf. em especial a tópica "Em torno da secularização da morte”, idem, p.338-352.

(22) “Ela [ a morte ] chega a ser até algo obsceno, um verdadeiro tabu." cf. MARCÍLIO, 1993 p.72.

(23) Coelho explora a relação da ideologia Positivista, na voz de seu nome maior, Auguste Comte, e o culto à morte: "O Positivismo em volga nesse momento possui no culto dos mortos como uma das características 
modelares do homem civil. Comte asseverava seu antigo reconhecimento que manifestamos pelo trabalho socialmente edificado de nossos predecessores.". Cf. COELHO, 1995.

(24) "Uma solenidade sem precedentes nos anais de nossa sociedade" assim classifica "O Globo" de 6 de maio de 1876 sobre as cerimônias fúnebres de Bastos. Rodrigues dedica-se a compreender o que foi esse momento, dando-Ihe um lugar privilegiado naquilo que ela chama como tensão entre a ascensão dos enterros civis em contrapartida aos enterros religiosos. A pesquisadora nos lembra que além de questões ideológicas (muitos eram anticlericais, maçons, socialistas ou republicanos laicos), os enterros civis, que nesse momento buscavam modos rituais - o discurso frente ao corpo do morto no cemitério, por exemplo - para fixar-se, também eram mais baratos. Cf. COELHO, 1995, p.199-213.

(25) Um óleo sobre tela de $224 \times 484$ centímetros no sentido horizontal, esticada na moldura - elemento indissociável de uma grande obra neste período - que é de madeira nobre entalhada em alto-relevo com motivos no estilo barroco romano; na parte superior central, o escudo da cidade de Belém, e na parte inferior, o brasão de armas do município, com uma lira de cinco cordas. O autor da moldura é o italiano Giuseppe Pucci, ligado ao ateliê romano de De Angelis e Capranesi. Sobre a tela, encontramos a assinatura "D. De Angelis" e, sob essa, outra assinatura: "Capranesi, Roma 1899". Dados observados na própria obra e confirmados em entrevista com a conservadora e responsável pelo acervo, Waldereis Araújo, em 31 de maio de 2006.

(26) "A imprensa, por isso mesmo, deu destaque para o expressivo número de autoridades e de personalidades da vida pública de Belém reunidas na casa do maestro nas horas que antecederam de imediato o seu falecimento, como registrou, ainda, o gesto de Lauro Sodré fechando-lhe os olhos tão logo dera-se o óbito."; cf. COELHO, 1995, p.123.

(27) Os retratos de homens célebres em seus leitos de morte usam diferentes modos de indicar a importância e a função histórica do retratado. Roupas, cenário, elementos de iluminações e expressão dos personagens são capazes desse feito. A famosa obra de Arthur William Devis, "A morte de Nelson", de 1807, que retrata a morte do mito militar mais importante da Grã-Bretanha, é um exemplo apropriado. A tela situa a força dramática - e, neste caso, semântica - da cena em seu cenário, o porão de um navio, e nos trajes militares de onze dos dezessete personagens em cena. O navio serve não apenas como índice histórico do fato, mas também como ícone alegórico do homem do mar e das batalhas.

(28) "A maior das notícias para nós, a única nacional, não preciso dizer que é a morte de Carlos Gomes. O telégrafo no-la deu, tão pronto se fecharam os olhos do artista e deu mais a notícia do efeito produzido em todo aquele povo do Pará, desde o chefe do Estado até o mais singelo cidadão. A triste nova era esperada - não sei se piedosamente desejada. [...]. Atentai, mais que tudo, para esse sentimento de unidade nacional. que a política pode alterar ou afrouxar, mas que a arte afirma e confirma, sem restrição de espécie alguma, sem desacordos, sem contrastes de opinião. A dor aqui é brasileira. Quando se fez a eleição do presidente da República, o Pará deu o voto a um filho seu, certo embora de que Ihe não caberia o governo da União; divergiu de S.Paulo. A república da arte é anterior às nossas constituições, superior às nossas competências. O que o Pará fez pelo ilustre paulista mostra a todos nós que há um só paraense e um só paulista que é este Brasil." Machado de Assis, Revista A Semana, 20 de setembro de 1896 (ASSIS, 1994).

(29) Enquanto o primeiro autor estuda e critica essa cena, o segundo a recupera e a ratifica. 
(30) Felipe Augusto Fidanza foi um dos difusores da fotografia na região norte do Brasil, fotografou a cidade de Belém durante quase quarenta anos, registrando as significativas transformações urbanas ocorridas na cidade na segunda metade do século 19, em decorrência da economia da borracha. Além da cidade de Belém, esteve também em Recife e Manaus. A sua atuação foi, como a maioria dos fotógrafos, na parte de fazer retratos, mas foi reconhecida pela qualidade técnica e nítida delicadeza de suas paisagens. Cf. MAGALHÃES; PEREGRINO, 2005.

(31) Ricardo Sales (1996) indica que o sistema acadêmico e as encomendas realizadas pelas diferentes instituições do Estado transformaram o modo como cada artista compunha suas obras, dando a elas elementos celebrativos que Ana Paula Simoni sintetizou na expressão "imagem oficial" (cf. SIMONI, 2002). O termo ornamental, surge, para Salles, como um modo de "arranjar" os elementos na obra de maneira a compor uma cena com o fim de alcançar os efeitos necessários a verossimilhança da época.

(32) Embora ainda matizada por preconceitos a respeito da produção acadêmica nas artes brasileiras daquele século, o estudo do Jeffrey Needell abre espaço para recompor os passos dados uma série de instituições e o modo como elas assimilam, promovem ou silenciam determinados elementos e processos da produção cultural, cf. NEEDELL, 1993.

(33) Mais uma vez a outra obra que recebe o mesmo tratamento quanto à programação visual é "Fundação da Cidade de Belém" (1908), de Theodoro Braga. Ela é a única obra que rivaliza com o quadro de De Angelis e Capranesi, cf. PREFEITURA..., 1997.

(34) Retratos de: José Coelho da Gama e Abreu - Barão do Marajó - e Gentil Bitencourt, ambos de Maurice Blaise, 1896 e 1894, respectivamente; o governador Paes Carvalho de Giovanni Grosso, 1900; o Intendente Arthur Índio do Brasil e Silva e o João Marques de Carvalho, ambas de De Angelis, de 1890 e 1900 , respectivamente; cf. PREFEITURA..., 1996.

(35) Henri Bergson escreveu que comicidade é uma antagonista da emoção, uma vez que, para ele, não é possível rir do que nos causa compaixão ou constrangimento. Para o filósofo francês não há comicidade fora daquilo que é humano em essência ou aparência, pois o riso é um fenômeno social, precisa de um eco; cf. BERGSON, 2001.

\section{Referências Bibliográficas}

ARIĖS, P. Sobre a história da morte no ocidente desde a Idade Média. Lisboa: Teorema, 1988.

ASSIS, M. Obras completas. Rio de Janeiro: Nova Aguilar, 1994. v.3.

BERGSON, H. Riso: ensaio sobre o significado da comicidade. Tradução Ivone Castilho Benedetti. São Paulo: Martins Fontes, 2001.

BETTENCOURT, Gastão de. A vida ansiosa e atormentada de um gênio: António Carlos Gomes. Lisboa: Clássica , 1945. 
BOSI, Alfredo. Um mito sacrificial: o indianismo de Alencar, In: Dialética da colonização. São Paulo: Cia. das Letras, 1992.

BREFE, A.C.F. O Museu Paulista: Affonso de Taunay e a memória nacional. São Paulo: Editora Unesp;Museu Paulista , 2005

CARVALHO, J. M. Formação das almas. São Paulo: Cia das Letras, 1995.

CASTRO, F. A representação da cidade de Belém no imaginário da literatura de seus espectadores ao longo do século XX. Disponível em <http://www.geocities.com/CollegePark/Field/2776/artig4.htm>. Acesso em: 19 mar. 2007.

CHARTIER, Roger. A aventura do livro: do leitor ao navegador. Tradução Reginaldo de Moraes. São Paulo: Editora Unesp / Imprensa Oficial do Estado de São Paulo, 1999.

CHOAY, F. A alegoria do patrimônio. Tradução Luciano Vieira Machado. São Paulo: Estação Liberdade / Editora Unesp, 2001.

COELHO, Geraldo M. O brilho de supernova: a morte bela de Carlos Gomes. Rio de Janeiro: Agir, 1995.

Quadros da Memória: Belém trezentos e oitenta anos. Belém: Prefeitura de Belém, 1996.

COLI, J. Como estudar a arte brasileira do século XIX? São Paulo: Editora Senac, 2005.

CRIMPT, Douglas. Sobre as ruínas do museu. Tradução Fernando Santos. São Paulo: Martins Fontes, 2005.

FERNANDES, J. Do sonho à conquista: revivendo um gênio da música - Carlos Gomes. São Paulo: Fermata do Brasil, 1978.

FIGUEIREDO, Aldrin Moura de. Memórias dos tempos de Landi: arte colonial e história republicana na Amazônia, 1888-1918. In: SEMINÁRIO LANDI E O SÉCULO XVIII NA AMAZÔNIA, 2003, Belém. Anais eletrônicos... Belém, 2003. Disponível em <http://www.landi.inf.br/anais>.

Theodoro Braga e a história da arte na Amazônia. In: PREFEITURA Municipal de Belém. Museu de Arte de Belém. A Fundação da Cidade de Belém. Belém: MABE, 2004, p. 31-87.

GALETTI, U.; CAMESASCA, E. Enciclopedia della pintura italiana. Itália: Aldo Garzanti, 1950.

KOSSOY, B. Realidade e ficções na trama fotográfica. São Paulo: Ateliê Editorial, 2000.

LOCKHART, Sharon. Teatro Amazonas. Rotterdam: Nai Publishers, 2000.

MAGALHÃES, A.;PEREGRINO, Nadja F. Fotografia no Brasil: um olhar das origens ao contemporâneo. Rio de Janeiro: Funarte, 2005. 
MAMMI, L. Carlos Gomes. São Paulo: Publifolha, 2001.

MARCÍLIO, M.L. A morte de nossos ancestrais In: MARTINS, J.S. (Org). A morte e os mortos na sociedade brasileira. São Paulo : Hucitec, 1983, p.171-181.

MARQUES, G. O homem da cabeça de leão: Carlos Gomes, suas músicas e seus amores. São Paulo: IHGSP, 1971.

NEEDELL, J. Belle-époque tropical: sociedade e cultura de elite no Rio de Janeiro na virada do século. São Paulo: Cia das Letras, 1993.

NOGUEIRA, L.W.M. Infância de Carlos Gomes. Revista Centro de Memória da Unicamp, Campinas, n.13, p.4960, 1996.

PÁSCOA, Márcio. A vida musical em Manaus na época da borracha (1850-1910). Manaus: Governo do Estado do Amazonas, 1997.

PREFEITURA Municipal de Belém. Fundação Cultural do Município de Belém, PA. Museu de Arte de Belém (MABE). Catálogo de Conservação do Museu de Arte de Belém: memória e inventário. Belém: MABE, 1996. (Série Caminhos da Cultura)

Tempo passado, tempo presente: acervo do Museu de Arte de Belém. Belém:

MABE/ Ministério da Cultura, 1997.

Museu de Arte de Belém: museu e acervo. Belém: MABE / Ministério da

Cultura, 2001. CD-ROM.

REIS, J.J. A morte é uma festa: ritos fúnebres e revolta popular no Brasil do século XIX. São Paulo : Cia das Letras, 1991.

RODRIGUES, C. Nas fronteiras do além: a secularização da morte no Rio de Janeiro (séculos XVIII e XIX). Rio de Janeiro: Arquivo Nacional, 2005.

SALLES, R. Nostalgia Imperial: a formação da identidade nacional no Brasil do Segundo Reinado. Rio de Janeiro: Topbooks, 1996.

SALLES, V. Carlos Gomes na Itália: pesquisa de Gaspare Nello Vetro. A província do Pará, Belém, 11, fev. 1996. .Obscuridades nas pompas fúnebres de Carlos Gomes. A província do Pará, Belém, 12, maio 1996.

SILVEIRA, Rose. O Theatro da Paz e sua história. Disponível em. <http://www.theatrodapaz.com.br/historico3.htm>. Acesso em 27 jul. 2006. 
SIMONI, A.P.C. Entre convenções e discretas ousadias: Georgina Albuquerque e a pintura histórica no Brasil. Revista Brasileira de Ciências Humanas, São Paulo, v.17, n.50, out. 2002. Disponível em: <http://www.scielo.br/scielo.php?script=sci_arttext\&pid=S0102-69092002000300009\#nt07>. Acesso em 19 mar. 2007.

SOUZA, M. Breve história da Amazônia. São Paulo: Marco Zero, 1994.

WHITE, H.; WHITE, C. Canvas and carrers: institucional change in the French painting world. Chicago: The University of Chicago Press, 1993.

ZOCCHI, Arnaldo. Opere e corredo artístico di GiovanniCapranesi. Reimpressão. Roma: Galeria de Arte Giacomini, 1991.

*Mestre em História da Arte pela Unicamp e aluno do Doutorado da Universidade de Brasília (UnB). O trabalho foi orientado pela Profa. Dra. Eleonora Zicari Costa de Brito e contou com recursos da CAPES.

Este trabalho é fruto de uma pesquisa realizada em Belém entre os meses de maio e junho de 2006. 